\title{
Exploration on Teaching Methods for Applied Optics Course of Printing Specialty
}

\author{
Qiang Liu (Corresponding author) \\ Lecturer, Department of Printing and Packaging, Wuhan University, Wuhan, China \\ E-mail: liuqiang@whu.edu.cn \\ Xiaoxia Wan \\ Professor, Department of Printing and Packaging, Wuhan University, Wuhan, China \\ E-mail:wan@whu.edu.cn
}

Xiaoli Yang

Lecturer, Science and Technology College of Hubei University for Nationalities, EnShi, China E-mail: xlyang2358@whu.edu.cn

Yanfen Zhang

Lecturer, Media Communication Department, Dongguan Polytechnic, Dongguan, China E-mail: zhangyf@dgpt.edu.cn

Received: July 8, 2015 Accepted: July 18, 2015 Published: August 10, 2015

doi:10.5296/jet.v2i2.8760 URL: http://dx.doi.org/10.5296/jet.v2i2.8760

\begin{abstract}
Printing engineering is an interdisciplinary specialty which involves a lot of intercross subjects such as optical engineering, information engineering, material science and engineering, mechanical engineering, control science and engineering, computer engineering, software engineering and so on. Nowadays, as those subjects progress, the content of printing engineering specialty is increasingly expanded, which places additional difficulty to the printing engineering education. The applied optics course of printing specialty aims at explaining the fundamental principles of optics which involve in printing-related domain. Therefore, it is of great significance for students to understand the basic imaging rules of the related equipments and thus further understand the whole subject. This study describes our teaching experience for applied optics course in school of printing and packaging, Wuhan University in China. The current teaching problems of the printing specialty as a whole were firstly collected by interview and questionnaire method. Afterwards, basing on the analysis of the problems, the specific teaching methods were proposed. The results showed that the teaching objectives were almost achieved and the vast majority of students were glad to accept such teaching methods.
\end{abstract}

Keywords: higher education, printing specialty, applied optics, teaching method 


\section{Introduction}

Printing engineering is a multidisciplinary subject. It is one engineering field in which several subjects cross, such as information, optics, computer, software, control, material, electron and even art (Chen, 2010). Recently, with the rapid development of the related technologies, the boundary of printing specialty becomes broader and broader. In today's printing industry, the commonly used devices includes not only various printers and finishing equipments, but also cameras, scanners, images setters, plate makers, standard lights and so on. That is why there are always students who complain that they have too many hard things to learn (Zhu \& Wang, 2013).

Generally speaking, the aim of printing process could be briefly expressed as to collect, record, store, transfer, render and release the visual information (Yi, Li, \& Chen, 2014). Therefore, it is easy to infer that explaining how the visual information forms and transfers among different media to students must be of great importance. The applied optics is just the course to interpret how light and color interacts with each other, so in recent years more and more universities in China which have set up the printing engineering specialty begin to adopt such course.

Wuhan University is a top ten university in China and her printing engineering education is in the domestic leading position among our country. Since the beginning of 2015, we began to introduce the applied optics course into our curriculum (Yi, Yuan, \& Wang, 2013) for the reasons mentioned above.

However, under the effect of various kinds of factors, we actually encountered a number of difficulties in our first semester. Firstly, since applied optics is a new adopted course, we had little fixed model for references. Although we had two related textbook at hand, the content in them is actually obsolete. That is, it is really true that we have to start from zero. Secondly, there is too much relevant knowledge embedding in the global scope of printing engineering, so we must grasp the main points and teach the lessons effectively. Besides, the students in our department do not major in optical engineering, so they probably find the lessons about basic optical principles hard to learn.

In order to conquer such problem, we had done some investigations before we designed the curriculum of the applied optics course. In our investigation, 30 fourth year students in our department were chose to participate in an interview while 40 third-year students were chose to participate in the questionnaire survey. In the interview and questionnaire survey, the students were asked to list the problems existing in their study and the research results actually provided us a lot of thoughts.

Basing on the analysis of the problems, the specific teaching methods were proposed. According to our curriculum design, the whole course of applied optics was divided into three parts: the theoretical learning part, the theoretical-practice learning part and the practice learning part. In each part, different teaching techniques were adopted such as flipped classroom (J. L. Zhang, Wang, \& B. H. Zhang, 2012), on-line learning (Peng, 2014), face-to-face discussion (Ellis, Goodyear, Prosser, \& O'Hara, 2006) and so on. Besides, we 
also combined our research projects with teaching, which greatly enhanced the students' learing interest. What's more, we tried our best to teach our students with the newest technology, as for the out-of-date topics in current textbook, they would be omitted.

After a semester of teaching, we found our exploration about the applied optics course quite successful. The results showed that the teaching objectives were almost achieved and the vast majority of students were glad to accept such teaching methods.

\section{Investigation}

In order to investigation the common problems of printing engineering education, the interview and questionnaire method (Liang, J. Y. Huang, H. Huang, \& Sheng, 2014) were implemented. 30 fourth year students and 40 third year students were invited to take part in interview and questionnaire respectively. Since the first and second year students have not learned enough professional lessons, they were not invited in this investigation.

\subsection{Interview survey and the results}

In the interview section, we talked to the 30 fourth year students who major in the printing engineering specialty one by one and asked them to list the problems existing in their study. Besides, we also encouraged them to express their thought about which kind of teaching methods they like best. The result of this interview seems straightforward and we could easily draw the following conclusions:

a. Most of the students stated that some of the courses in printing engineering specialty were too abstract to understand.

b. Nearly all the students pointed out that many of the devices mentioned in the test book were out of date, while for the newest equipments and technologies, they could not learn from their teachers.

c. A lot of students mentioned that they felt several lessons of this specialty actually dull and therefore they did not like them.

d. Several students complained that the teachers spent too much time talking about the knowledge points in the slides, which made them hard to concentrate.

e. Certain advance students suggested us to add more experimental lessons.

\subsection{Questionnaire survey and the results}

In the questionnaire section, we asked 40 third year students who major in the printing engineering specialty similar questions and invited them to choose the appropriate options listed in a table. Note that there are ten options in the table and for each student he can choose no more than 5 options in it.

The results of this questionnaire section were summarized in Table 1. When comparing the investigation result of the interview and questionnaire survey, we found that the reflection of the fourth and third year students differed slightly. A possible explanation about this phenomenon is that the fourth year students had participated in more difficulties lessons and 
therefore they reflected more problems. Meanwhile, it is also easy to conclude that the two surveys also show many similar trends. For instance, the majority of those students were desired to learn newest knowledge and they did not like to learn the out of date technologies. In addition, students also want us to add more examples and experiments into the courses. Besides, 60\% third year students mentioned that they were puzzled about the principles, which further strengthened our mind to provide a sound applied optics course this year.

Table 1. The main problems revealed by the Questionnaire survey for printing specialty students

\begin{tabular}{ccc}
\hline Problem & Number of student & Percentage (\%) \\
\hline Difficult to learn & 12 & 30.0 \\
Boring content & 16 & 40.0 \\
Lack of examples & 21 & 52.5 \\
Puzzled about the principles & 24 & 60.0 \\
Lack of experiment & 11 & 27.5 \\
Out of date knowledge & 26 & 65.0 \\
Lack of interests & 17 & 42.5 \\
\hline
\end{tabular}

\section{Methodology}

Basing on the former findings of the interview and questionnaire survey, the curriculum design of applied optics course was implemented. During this process, several teaching concepts (Byrne \& Flood, 2004, Dahlin \& Regmi, 1997, Franz et al., 1996, Martin, Trigwell, Prosser, \& Ramsden, 2003, Marton \& Booth, 1997) provided us successful experience for reference.

\subsection{Content planning}

Since the latest textbook of applied optics for printing engineering specialty was published in 2007 (Xu, 2007), much of the technical information in it has been out of date. But for the theoretical part, such textbook could be actually adopted. Therefore, since we don't have other choices, we finally decided to used it as our textbook and add new things into the class when needed.

To make the balance between theory and practice, the whole course (36 class hours) was divided into three parts:

a. The theoretical learning part (15 class hours), in which we will teach the fundamental of geometrical optics, such as the coaxial spherical optical system, the perfect optical system, the plane mirror prism system, the beam of the optical system and so on. Besides, the introduction of Photometry will also be introduced.

b. The theoretical-practice learning part (15 class hours), in which we will teach the optical imaging principles of various equipments, such as laser printers, scanners, 
plate makers, cameras and so on. Besides, it is worth to mention that the introduction of those equipments will be related with the rules in the theoretical learning part.

c. The practice learning part (6 class hours), in which we will instruct the students to proceed scientific experiments and thus cement the knowledge in their mind.

\subsection{Teaching methods development}

In order to solve the above mentioned problems collected from the students, we designed the following teaching methods.

a. In the theoretical learning part, we were strict with the students and asked them to learn the formula deduction process by heart. Since the theoretical part is the fundamental of the whole course, we must make sure that all of the students will grasp such knowledge.

b. In the theoretical-practice learning part, the newest technologies were introduced in our lessons. For instance, when teaching the traditional laser technology, we introduced the latest holography imaging skills to students and at that time nearly all of the students listened carefully.

c. In the experimental learning part, we attempted to combine the teaching process and scientific research together. For example, in order to deepen the students' understanding about light sources and photometry, we instructed them to implement the photometric measurement on a spectrally tunable LED light with a spectral radiometer. Since the color of the experimental LED light could change continually, most of the students were attracted by it during the experiment.

d. To cultivate student' interest, an expert of industry was invited to our class to share his experience. In that class, we had a strong feeling that when faced with an expert who came from industry, the students felt much more real about what they learned.

e. We also brought the flipped classroom method as well as on-line learning method into our class, which actually aroused the enthusiasm of the students.

\section{Discussion and Conclusion}

Frankly speaking, preparing for the applied optics course actually took up most of our time. Fortunately, after a semester's teaching, our exploration about the teaching methods for applied optics course seems to be quite successful. Our initial objectives (for instance, class attendance, classroom discipline, students' concentration, learning interests, classroom activity, etc) were almost achieved and all of the students passed the exam successfully. Recently, we know from several students that the vast majority of them were glad to accept such teaching methods.

Meanwhile, although we have gained primary success in this course, there are still many problems. 
a. The textbook is till obsolete and there is an urgent need for a new one.

b. Since the students do not major in optical engineering, they always find the theoretical lessons hard to learn.

c. Because of the continuous development of printing related technology, the content of the applied optics course should vary according, which everlastingly places burden to the educators.

To sum up, the applied optics course is of great significance for students to understand the basic imaging rules of the printing process and thus further understand the printing engineering specialty. Therefore, special attentions will be paid to those unsolved problems and we will constantly strive for excellence

\section{Acknowledgement}

This study was supported by the Teaching Research Project of Science and Technology College of Hubei University for Nationalities (KJY201402).

\section{References}

Byrne, M., \& Flood, B. (2004). Exploring the conceptions of learning of accounting students. Accounting Education, 13, 25-37.

Chen, G. X. (2010). Thoughts on the discipline connotation and system of printing specialty. China Printing and Packaging Study, 2(4), 1-12. (in Chinese)

Dahlin, B., \& Regmi, M. P. (1997). Conceptions of learning among Nepalese students. Higher Education, 33(4), 471-493.

Ellis, R. A., Goodyear, P., Prosser, M., \& O'Hara, A. (2006). How and what university students learn through online and face - to - face discussion: Conceptions, intentions and approaches. Journal of Computer Assisted Learning, 22(4), 244-256.

Franz, J., Ferreira, L., Loh, H., Pendergast, D., Service, M., Stormont, D., ... Williamson, B. (1996). Students' and lecturers' conceptions of learning in context: an interdisciplinary study. Teaching in Higher Education, 1(3), 325-339.

Liang, J., Huang, J. Y., Huang, H., \& Sheng, L. (2014). Problems of teaching process and improvement of teaching methods for printing chromatics course. China Printing and Packaging Study, 6(4), 23-28. (in Chinese)

Martin, E., Trigwell, K., Prosser, M., \& Ramsden, P. (2003). Variation in the experience of leadership of teaching in higher education. Studies in Higher Education, 28, 247-259.

Marton, F., \& Booth, S. (1997). Learning and Awareness. Mahwah, NJ: Lawrence Erlbaum Associates.

Peng, T. (2014). The analysis about how to improve the efficiency of utilization of teaching resource in colleges. Journal of Jiang Han University: Social Science Edition, 31(1), 97-102. (in Chinese) 
Xu, Y. F. (2007). Applied Optics for Printing Engineering. BJ. Press culture development company, LTD.

Yi, Y. H., Li, Z. J., \& Chen, C. M. (2014). Analysis on Changes of Talent demands in modern printing engineering technology field. China Printing and Packaging Study, 4(6), 1-4. (in Chinese)

Yi, Y. H., Yuan, Y., \& Wang, Y. L. (2013) Research on innovative talents training model of industry-university-research cooperation for printing engineering specialty. China Printing and Packaging Study, 5(4), 80-84. (in Chinese)

Zhang, J. L., Wang, Y., \& Zhang, B. H. (2012). Research on the teaching mode of flipped classroom. Distance Education Journal, 4, 45-61. (in Chinese)

Zhu, M., \& Wang, L. (2013) Discussion on training model of the practical graduate talents for printing engineering major. China Printing and Packaging Study, 5(4), 75-79. (in Chinese)

\section{Copyright Disclaimer}

Copyright reserved by the author(s).

This article is an open-access article distributed under the terms and conditions of the Creative Commons Attribution license (http://creativecommons.org/licenses/by/3.0/). 